\title{
Editorial
}

\section{Antiarrhythmic drugs in the management of atrial fibrillation}

Antiarrhythmic drug therapy in the post-CAST era ${ }^{12}$ has undergone a period of uncertainty and re-evaluation. The role of antiarrhythmic drugs in the management of less serious arrhythmias has come into question. If an arrhythmia is not life-threatening it is paramount that it should not be made so through inappropriate treatment. This issue is particularly pertinent to the management of atrial fibrillation-the commonest of arrhythmias and one which in the absence of pre-excitation is not directly life-threatening. Yet the symptomatic limitations and morbidity imposed by atrial fibrillation are often severe and the need for effective and safe treatment is selfevident.

\section{Restoration of sinus rhythm}

In patients with recent onset of atrial fibrillation, sinus rhythm can often be restored pharmacologically. Digitalis, the traditional treatment, does not have a primary anti-fibrillatory action. On the contrary digitalis glycosides through their vagomimetic effects might be expected to be pro-fibrillatory. ${ }^{3}$ Not surprisingly, therefore, digoxin has been found to be no more effective than placebo in reverting atrial fibrillation to sinus rhythm. ${ }^{4}$

In contrast class I and class III drugs in the Vaughan Williams classification do have a direct anti-fibrillatory action. Treatment is most successful in patients with recent onset of atrial fibrillation. Intravenous flecainide, for example, converted $60-80 \%$ patients with recent onset atrial fibrillation to sinus rhythm ${ }^{5-7}$ and intravenous amiodarone converted $70-80 \% .^{8-10}$ Treatment is not without potential problems. Class I agents can adversely affect ventricular function ${ }^{11}$ or induce a slow atrial flutter with 1 to 1 conduction into the ventricle. ${ }^{12}$ Intravenous amiodarone can cause hypotension. ${ }^{13}$ However, unlike long-term antiarrhythmic therapy these risks are immediate and are not a major hazard when the physician is both aware and vigilant.

In appropriately selected patients antiarrhythmic treatment is therefore a reasonable alternative to DC cardioversion. It would be unwise, however, to advocate that class I or class III agents should completely replace digoxin in the management of new onset atrial fibrillation. In some patients there is no immediate need to restore sinus rhythm and ventricular rate control alone may be adequate: digitalisation is still appropriate for this purpose.

\footnotetext{
Maintenance of sinus rhythm

Digoxin is ineffective in preventing recurrences of atrial fibrillation. ${ }^{14}$ In contrast, both class I and class III agents are of value. When one specific drug fails there is still a case for assessing other agents because the arrhythmogenic mechanisms underlying atrial fibrillation vary from patient to patient and result in different responses to different drugs. ${ }^{15}$

Quinidine, for many years the traditional therapy in the United States, is of proven efficacy, ${ }^{16}$ - but at a cost.
}

The dangers of torsades de pointes when treatment starts are well recognised and meta-analysis has suggested the possibility of an excess mortality in patients on quinidine therapy..$^{16}$ It is questionable, therefore, whether a role for quinidine in the prophylaxis of atrial fibrillation can still be justified.

The class Ic agents flecainide and propafenone are gaining in popularity for prophylaxis. Once again their efficacy is proven, ${ }^{17-20}$ but can we be equally convinced about their safety? It is clear that we should avoid giving class Ic drugs to patients who resemble those recruited to CAST. Unfortunately, it is unclear which features of CAST patients predisposed them to arrhythmias. We do not know whether risks are confined to the particular patient population studied-that is, to patients with previous myocardial infarction and frequent ventricular extrasystoles - or whether they extend to all patients with previous infarction, coronary disease, or indeed any form of structural heart disease. Many patients with atrial fibrillation have underlying myocardial or coronary disease and it cannot be asserted that class Ic therapy carries no risk. Serious ventricular arrhythmias and sudden death have been reported in the management of supraventricular arrhythmias, including atrial fibrillation. ${ }^{21}{ }^{22}$ While it might be anticipated that risks would be greater among patients with structural heart disease, they are not confined to this group. Life-threatening arrhythmias have also been reported among patients with lone atrial fibrillation, ${ }^{23}$ and no group of patients can be considered as completely free from risk. Despite these considerations there is no evidence of an excess in population mortality when class Ic agents are used to treat supraventricular arrhythmias. ${ }^{24}$

Class III antiarrhythmic therapy is also of proven value in prophylaxis. The archetypal agent, amiodarone, is particularly effective ${ }^{25} 26$ but has gained notoriety on account of its high incidence of side effects and occasional cases of pulmonary fibrosis. Whether this reputation is fully deserved in the management of atrial fibrillation is open to question because many patients are satisfactorily controlled on low doses of amiodarone of $200 \mathrm{mg}$ daily or less. At these doses, though less serious side effects are still common, serious side effects are rare. ${ }^{27}$ The risks of proarrhythmia are substantially less with amiodarone than with other antiarrhythmic agents. ${ }^{28}$

Sotalol is gaining in popularity as an acceptable alternative to amiodarone. The recent success of sotalol in comparison with other antiarrhythmic agents in the management of serious ventricular arrhythmias in the ESVEM study ${ }^{29}$ adds to the general attractions of this drug. The drug is as effective as quinidine in prophylaxis. ${ }^{30}$ Even sotalol, however, carries a proarrhythmic risk, and may induce torsades de pointes. ${ }^{31}$ The extent to which the antiarrhythmic benefits of sotalol are related to its class III action is open to question because the doses required to achieve $\beta$ blockade and to prolong repolarisation are not equivalent. At low doses $\beta$ blockade predominates ${ }^{32}$ and it is possible that antiarrhythmic benefits merely reflect this action. If so, other 
$\beta$ blockers might prove as effective and avoid the risk of proarrhythmic complications.

There are potential risks associated with any prophylactic drug therapy and the magnitude of these risks is unknown. For this reason, before treatment is started the benefits and risks in an individual patient must be carefully appraised. Patients with heart failure may be at particular risk. ${ }^{33}$

\section{Control of ventricular rate}

The limitations of digoxin for rate control in atrial fibrillation are well recognised. Digoxin has little effect on peak heart rate at maximum exercise. ${ }^{34} \beta$ Blockers, in contrast, do limit heart rate at peak exercise. Somewhat disappointingly, however, this has generally not been reflected in an improvement in exercise tolerance. ${ }^{3536}$ Because of this and because of the difficulties of using $\beta$ blockers in patients who often have underlying ventricular impairment, digoxin continues to be a mainstay of treatment. When digoxin alone proves inadequate, the addition of a $\beta$ blocker or calcium antagonist can prove synergistic in improving the rate control. ${ }^{37}$ The partial $\beta$ agonist xamoterol, which initially held much promise in the treatment of atrial fibrillation, ${ }^{38} 39$ has fallen into disfavour because of the increased mortality associated with its use in patients with heart failure. ${ }^{40}$

\section{The future}

Whereas the limitations of drug therapy in the management of atrial fibrillation are readily apparent the successes should also be recognised. The success of newer treatments poses a particular problem because the risks of therapy are so ill-defined. It cannot be denied that treatment carries the potential for an increased mortality, yet there may also be prognostic benefits in successful drug treatment. Maintenance of sinus rhythm may reduce the thromboembolic risk. Superior rate control may prevent deterioration of left ventricular function..$^{1142}$ Whatever the net effect on prognosis, withholding treatment may condemn patients to an unnecessary morbidity.

The ideal would be to develop new antiarrhythmic drugs without proarrhythmic risk. This is fundamentally not achievable because the same properties that protect against arrhythmias in some patients will cause them in others. ${ }^{43}$ Considerable research is currently being directed to the development of new class III agents, which it is hoped will offer the benefits of amiodarone without its side effects. Several drugs are being evaluated. The question remains whether future class III agents will carry a greater risk of torsades de pointes than amiodarone. This issue is of particular importance in the management of atrial fibrillation. While some risk of proarrhythmia might be acceptable in the management of life-threatening ventricular arrhythmias, a similar risk would be unacceptable in the management of atrial fibrillation.

It is possible therefore that future antiarrhythmic drugs will confer no advantages over those currently available. For this reason, we need to define more precisely the risks and benefits of available drugs. Recent wellcontrolled studies of warfarin and aspirin treatment in patients with atrial fibrillation have led the way and clarified the benefits and risks of anticoagulation. ${ }^{44} \mathrm{~A}$ similar approach is now needed with antiarrhythmic treatment.

Department of Cardiology

The General Infirmary at Leeds,

Leeds LS1 3EX
1 The CAST Investigators: Effect of encainide and flecainide on mortality in a randomized trial of arrhythmia suppression after myocardial infarction. $N$ Engl $\mathcal{F}$ Med 1989;321:406-12.

2 The CAST Investigators: The cardiac arrhythmia suppression trial: First CAST . . . then CAST 2. $\mathcal{F}$ Am Coll Cardiol 1992;19:894-8.

3 Podrid PJ. Oral antiarrhythmic drugs used for atrial fibrillation: clinical pharmacology. In: Falk RH, Podrid PJ, eds. Atrial fibrillation. Mechanisms and management. New York:Raven Press, 1992:197-231.

4 Falk RH, Knowlton AA, Bernard SA, Gotlieb NE, Battinclli NJ. Digoxin for converting recent-onset atrial fibrillation to sinus rhythm. A randomized, double-blinded trial. Ann Intern Med 1987;106:503-6.

5 Nathan AW, Camm AJ, Bexton RS, Hellstrand KJ. Intravenous flecainide acetate for the clinical management of paroxysmal tachycardias. Clin Cardiol 1987;10:317-22.

6 Suttorp MJ, Kingma H, Jessurun ER, Lie-A-Huen L, van Hemel NM, $\mathrm{Lie} \mathrm{KI}$. The value of Class IC antiarrhythmic drugs for acute conversion of paroxysmal atrial fibrillation or flutter to sinus rhythm. $f \mathrm{Am}$ Coll Cardiol 1990;16:1722-7.

7 Donovan KD, Dobb GJ, Coombs LJ, Lee K-Y, Weekes JN, Murdock CJ, et al. Reversion of recent-onset atrial fibrillation to sinus rhythm by intravenous flecainide. Am f Cardiol 1991;67:137-41

8 Faniel R, Schoenfeld $\mathrm{Ph}$. Efficacy of i.v. amiodarone in converting rapid atrial fibrillation and flutter to sinus rhythm in intensive care patients. Eur Heart $\mathcal{1}$ 1983;4:180-5.

9 Cowan JC, Gardiner P, Reid DS, Newell DJ, Campbell RWF. A comparison of amiodarone and digoxin in the treatment of atrial fibrillation complicating suspected acute myocardial infarction. $f$ Cardiovasc Pharmacol 1986;8:252-6.

10 Noc $M$, Stajer $D$, Horvat $M$. Intravenous amiodarone versus verapamil for acute conversion of paroxysmal atrial fibrillation to sinus rhythm. Am $\mathcal{f}$ Cardiol 1990;65:679-80.

11 Bourke JP, Cowan JC, Tansuphaswadikul S, Campbell RWF. Antiarrhythmic drug effects on left ventricular performance. Eur Heart $\mathcal{f}$ 1987;8(suppl A): $105-11$.

12 Marcus FI. The hazards of using type 1C antiarrhythmic drugs for the treatment of paroxysmal atrial fibrillation. Am $\mathcal{F}$ Cardiol 1990;66:366-7.

13 Rotmensch HH, Belhassen B. Amiodarone in the management of cardiac arrhythmias: current concepts. Med Clins N Am 1988;72:321-58.

14 Rawles JM, Metcalfe MJ, Jennings K. Time of occurrence, duration, and ventricular rate of paroxysmal atrial fibrillation: the effect of digoxin. $\mathrm{Br}$ Heart f 1990;63:225-7.

15 Crijns HJ, van Gelder IC, van Gilst WH, Hillege H, Gosselink AM, Lie $\mathrm{KI}$. Serial anti-arrhythmic drug treatment to maintain sinus rhythm after electrical cardioversion for chronic atrial fibrillation or atrial flutter. Am $\mathcal{F}$ Cardiol 1991;68:335-41.

16 Coplen SE, Antman EM, Berlin JA, Hewitt P, Chalmers TC. Efficacy and safety of quinidine therapy for maintenance of sinus rhythm after and safety of quinidine therapy for maintenance of sinus rhythm after 1990;82:1106-16.

17 van Gelder IC, Crijns HJGM, van Gilst WH, van Wijk LM, Hamer HPM, Lie KI. Efficacy and safety of flecainide acetate in the maintenance of sinus rhythm after electrical cardioversion of chronic atrial fibrillation or atrial flutter. Am $\mathcal{F}$ Cardiol 1989;64:137-1321.

18 Henthorn RW, Waldo AL, Anderson JL, Gilbert EM, Alpert BL Bhandari AK, Hawkinson RW, Pritchett ELC and the Flecainide Supraventricular Study Group. Flecainide acetate prevents recurrence of symptomatic paroxysmal supraventricular tachycardia. Circulation 1991;83:119-25.

19 Pietersen $\mathrm{AH}$, Hellemann $\mathrm{H}$ for the Danish-Norwegian Flecainide Multicentre Study Group. Usefulness of flecainide for prevention of paroxysmal atrial fibrillation and flutter. $A m \mathcal{F}$ Cardiol 1991;67:713-7.

20 Pritchett ELC, McCarthy EA, Wilkinson WE. Propafenone treatment of symptomatic paroxysmal supraventricular arrhythmias: a randomised, placebo-controlled, crossover trial in patients tolerating oral therapy. Ann Intern Med 1991;114:539-44

21 Sihm I, Hansen FA, Rasmussen J, Pedersen AK, Thygesen K. Flecainide acetate in atrial flutter and fibrillation. The arrhythmogenic effects. Eur Heart $\mathcal{F} 1990 ; 11: 145-8$.

22 Feld GK, Chen P-S, Nicod P, Fleck P, Meyer D. Possible atrial proarrhythmic effects of Class $1 \mathrm{C}$ antiarrhythmic drugs. Am $\mathcal{F}$ Cardiol 1990;66:378-83.

23 Falk RH. Flecainide-induced ventricular tachycardia and fibrillation in patients treated for atrial fibrillation. Ann Intern Med 1989;111:107-11.

24 Pritchett ELC, Wilkinson WE. Mortality in patients treated with flecainide and encainide for supraventricular arrhythmias. Am $\mathcal{f}$ Cardiol 1991;67:976-80.

25 Middlekauff HR, Wiener I, Saxon LA, Stevenson WG. Low-dose amiodarone for atrial fibrillation: Time for a prospective study? Ann Intern Med 1992;116:1017-20.

26 Gosselink ATM, Crijns HJGM, van Gelder IC, Hillige H, Wiesfeld ACP, Lie KI. Low-dose amiodarone for maintenance of sinus rhythm after cardioversion of atrial fibrillation. $f A M A$ 1992;267:3289-93.

27 Dusman RE, Stanton MS, Miles WM, Klein LS, Zipes DP, Fineberg NS, et al. Clinical features of amiodarone-induced pulmonary toxicity. Circulation 1990;82:51-9.

28 Middlekauff HR, Stevenson WG, Stevenson LW, Saxon LA Antiarrhythmic drug therapy in 367 advanced heart failure patients: class I drugs but not amiodarone are associated with increased sudden death risk [abstr]. $₹$ Am Coll Cardiol 1991;17:92.

29 The ESVEM Investigators. Determinants of predicted efficacy of antiarrhythmic drugs in the electrophysiologic study versus electrocardiorhythmic drugs in the electrophysiologic study

30 Juul-Moller S, Edvardsson N, Rehnqvist-Ahlberg N. Sotalol versus quinidine for the maintenance of sinus rhythm after direct current conversion dine for the maintenance of sinus rhythm after dir.

31 McKibben JK, Pocock WA, Barlow JB, Scott Millar RN, Obel IWP. Sotalol, hypokalaemia, syncope and torsade de pointes. Br Heart $\dot{f}$ 1984;51:157-62

32 Woosley RL, Barbey JT, Wang T, Funck-Brentano C. Concentration /response relations for the multiple antiarrhythmic actions of sotalol Am 7 Cardiol 1990;65(Suppl A):22-7.

33 Flaker GC, Blackshear JL, McBride R, Kronmal RA, Halperin JL, 
Hart RG. Antiarrhythmic drug therapy and cardiac mortality in atrial fibrillation. $\mathcal{f}$ Am Coll Cardiol 1992;20:527-32.

34 Redfors A. Digoxin dosage and ventricular rate at rest and exercise in patients with atrial fibrillation. Acta Med Scand 1971;190:321-33.

35 DiBianco R, Morganroth J, Freitag RJ, et al. Effects of nadolol on the spontaneous and exercise-provoked heart rate in patients with chronic atrial fibrillation receiving stable doses of digoxin. Am Heart $\mathcal{f} 1984 ; 108$ : atrial fib $1121-7$.

36 Atwood JE, Sullivan M, Forbes $\mathrm{S}$, et al. Effect of beta-adrenergic blockade on exercise performance in patients with chronic atrial fibrillation. $\mathcal{F} \mathrm{Am}$ Coll Cardiol 1987;10:314-20.

37 Sarter BH, Marchlinski FE. Redefining the role of digoxin in the treatment of atrial fibrillation. Am $\mathcal{f}$ Cardiol 1992;69:71G-81G.

38 Molajo AO, Coupe MO, Bennett DH. Effect of Corwin (ICI 118587) on resting and exercise heart rate and exercise tolerance in digitalized patients with chronic atrial fibrillation. Br Heart $\mathcal{f} 1984 ; 52: 392-5$.
39 Ang EL, Chan WI, Cleland JGF, et al. Placebo controlled trial of xamoterol versus digoxin in chronic atrial fibrillation. Br Heart $71990 ; 64$ : 256-60.

40 The Xamoterol in Severe Heart Failure Study Group. Xamoterol in severe heart failure. Lancet 1990;336:1-6.

41 Peters KG, Kienzle MG. Severe cardiomyopathy due to chronic rapid atrial fibrillation: complete recovery after reversion to sinus rhythm. $\mathrm{Am}$ atrial fibrillation: complete recovery after reversion to sinus rhythm. Am

42 Abbott JA, Schiller NM, Ilvento JB, et al. Catheter ablation of atrioventricular conduction may improve left ventricular function and cause minimal aortic valve damage. $P A C E$ 1987;10:411.

43 Cowan JC, Baig W, Tan L-B. Adverse drug reactions on the heart. In: Davies D, ed. Textbook of adverse drug reactions. Oxford: Oxford University Press, 1991:99-147.

44 Nolan J, Bloomfield P. Non-rheumatic atrial fibrillation: warfarin or aspirin for all? Br Heart $\mathcal{F}$ 1992;68:544-8. 